PROBLEMS

OF EDUCATION

IN THE $21^{\text {st }}$ CENTURY

Volume 56,2013

\title{
CHARACTERISTIC OF THE MOST POPULAR MOVIE CHARACTERS AMONG CHILDREN - EDUCATIONAL CONTEXTS
}

Tomasz Huk

University of Silesia, Katowice, Poland

E-mail: tomasz.huk@us.edu.pl

\begin{abstract}
Mass media play an essential role at almost every stage of human's life. The media have a particular influence on children who are not entirely aware of their message. A part of reality surrounding children was examined in order to determine the features of favourite movie characters and preferable situations in which said a character participates. The results obtained through a diagnostic survey indicate that there is a statistically significant difference between girls and boys choices of a movie character. This article focuses on the aspects of using children's favourite characters by a teacher in education. The presented discussion regarded also the problem of children emulating movie characters.
\end{abstract}

Key words: movie character, education, gender, and media.

\section{Introduction}

Nowadays media are a constant element of children's social and cultural functioning. A film, which is accessible not only in the cinema and television but also via data carriers and Internet on computers, tablets and smartphones, plays a special role in the use of media by children.

In the films watched by children we can distinguish characters which through their appearance and behaviour create a specific set of acceptable features that can become a certain indicator for children's fashion, behaviour and subject of conversation. Film studios' screenwriters, who take advantage of children's vulnerability to influences, very often use this mechanism. While creating a plot they follow a particular pattern, which use guarantees success, both cinematic and marketing. Sometimes the most popular movie characters among children are the subject of companies' campaigns the main objective of which is a capital gain from the sale of various gadgets.

Along with the increase of the number of data carriers (pen drive, DVD disc, Internet) available for children, changes the variety of accessible contents. Currently, a considerable part of the media industry is dedicated to producing and distributing contents intentionally addressed to children. Television stations make personalized TV channels that broadcast fiction and animated films promoting a "fashionable lifestyle". With such a big scale of film productions, it is not surprising that young people dedicate a lot of time to media (Roberts \& Foehr, 2008). The fact that children watch the same films or TV programmes result from their common interests (Dorr et. al., 1990) and contributes to the deepening of friendship.

Teachers in learning process rarely use the popularity of film and its character among children. They implement a predetermined curriculum, which hardly ever assumes the use of psychical and physical attributes of characters from films, which are currently on the top. After all, media education should be conducted also at school (Frania, 2012). Teachers should be aware that in their late childhood the young audience enters the world of public programmes, 
also those intended for adults (Roberts, et. al., 2005), we should remember that emulated and loved movie characters often act on contrary to accepted system of values.

The diversity in the raised issue was an inspiration to examine an aspect which considers the type of movie characters preferred by children between the age of 10-12. Defining several distinctive features of these characters and their typical behaviour may become an element of constructing an educational programme and also adopting particular attitudes by teachers towards students.

Following research problems were formulated: - What are the preferred by children between the ages 10-12 features and behaviours of a movie character? - Is there any difference in girls' and boys' preferences, between the ages of 10-12 considering a movie character? - If there is such a difference, then what elements diversify the preferred movie characters of boys and girls between the ages of 10-12?

\section{Methodology of Research}

The research area is a range of reality which contains interests and preferences of children aroused from film reception. Most often research in this subject is conducted in the context of Albert Bandbury's social learning theory (1986). Biskup and Pfister (1999) stated how significant popular movie characters are among children. Surveying 44 girls and 53 boys from 5 different primary schools in Berlin, they asked the following questions: "Is there anyone you consider your role model?", "who is and what role plays your role model?" Results of the conducted research enabled describing models, where boys chose mainly sportsmen and movie characters, and girls chose their music idols.

The research had a quantitative character and was based mainly on the survey conducted among 102 children, 61 girls and 41 boys, between the ages of 10-12. They come from a Polish city having 360 thousand inhabitants and live in averagely wealthy families. Obtained results underwent a statistical analysis. In order to establish the relation between the gender of surveyed children and their preferences connected with movie character test $\chi^{2}$ was implemented. Also, the strength of the relation between variables examined with the help of the $r_{c}$ coefficient was estimated (Guilford, 1964).

\section{Results of Research}

Most children identify themselves with characters presented in fiction or animated movies (Table 1). It might be the main or supporting character and even the less important ones. Research has shown that girls generally identify with female $(69.8 \%)$ and boys with male $(85.4 \%)$ characters. It is worthwhile noticing that girls' opinions are not the reflection of those of boys, as girls $(30.2 \%)$ more often than boys $(14.6 \%)$ identify with the characters of opposite gender. Differences in the statements of both genders are noticeable in their choice considering preferred character's age. $81.4 \%$ of girls like when a character is a child or a teenager while the same choice was made merely by $39 \%$ of boys.

The appearance is also significant to respondents. As much as $90.4 \%$ of them prefer when a character represents specific a beauty canon $-75 \%$ of children identify with human characters rather than with those of other nature like animals, creatures, aliens, etc. However, it is necessary to add that considerably more boys than girls prefer a character that is not a human being. The majority of respondents $(61 \%)$ expect characters to have some supernatural powers, which are required more often by girls $(71.4 \%)$ rather than boys $(46.3 \%)$. 
Tomasz HUK. Characteristic of the Most Popular Movie Characters among Children - Educational Contexts

PROBLEMS

OF EDUCATION

IN THE $21^{\text {st }}$ CENTURY

Volume 56, 2013

Table 1. Features of movie character preferred by children between the age of 10-12.

\begin{tabular}{lllllll}
\hline & Girls & Boys & 10-year-olds & 11-year-olds & 12-year-olds & Overall \\
\cline { 2 - 7 } & $\%$ & $\%$ & $\%$ & $\%$ & $\%$ & $\%$ \\
\hline Is a girl & 69.80 & 14.60 & 46.30 & 46.80 & 43.75 & 48.10 \\
\hline Is a boy & 30.20 & 85.40 & 53.70 & 53.20 & 56.25 & 51.90 \\
\hline Is a child, a teenager & 84.10 & 39.00 & 60.90 & 29.70 & 75.00 & 67.30 \\
\hline Is adult person & 15.90 & 61.00 & 39.10 & 70.30 & 25.00 & 32.70 \\
\hline Is pretty & 90.40 & 87.80 & 97.60 & 91.50 & 68.75 & 90.40 \\
\hline Is ugly & 9.60 & 12.20 & 2.40 & 8.50 & 31.25 & 9.60 \\
\hline Is human being & 82.50 & 65.90 & 70.70 & 80.85 & 75.00 & 75.96 \\
\hline Is not human being & 17.50 & 34.10 & 29.30 & 19.15 & 25.00 & 24.04 \\
\hline $\begin{array}{l}\text { Possesses supernatural } \\
\text { powers }\end{array}$ & 71.40 & 46.30 & 70.70 & 53.20 & 62.50 & 61 \\
\hline Is ordinary person & 28.60 & 53.70 & 29.30 & 46.80 & 37.50 & 39 \\
\hline
\end{tabular}

The results obtained made it possible to determine also movie situations preferred among children between the ages of 10-12 (Table 2). These situations make up a set of likings, including behaviour acceptable in particular circumstances. On the base of implemented research we can indicate that the vast majority of girls and boys prefer when a character: fights, hurts or kills negative characters, which represent "evil". However, it is worthwhile noticing that those are not preferences of all surveyed children. Part of them $(9.7 \%-10.6 \%)$ claim that their movie character should fight, hurt or kill "good" characters. Preferring such a type of behaviour occurs more often with boys than girls. Therefore, it can be noticed that some of the respondents may have problems with aggression, an issue that was extensively introduced by A. Bandura, Dorothea Ross and Sheila A. Ross (1963).

Table 2. Behaviour of the movie character preferred by children aged 10-12.

\begin{tabular}{lllllll}
\hline & Girls & Boys & 10-year-olds & 11-year-olds & 12-year-olds & Overall \\
\cline { 2 - 7 } & $\%$ & $\%$ & $\%$ & $\%$ & $\%$ & $\%$ \\
\hline Fights evil & 95.20 & 87.80 & 95.20 & 91.40 & 87.50 & 92.30 \\
\hline Fights good & 4.80 & 12.20 & 4.80 & 8.60 & 12.50 & 10.60 \\
\hline $\begin{array}{l}\text { Inflicts pain on "evil" } \\
\text { characters }\end{array}$ & 95.20 & 82.90 & 95.10 & 85.10 & 93.75 & 90.30 \\
\hline $\begin{array}{l}\text { Inflicts pain on "good" } \\
\text { characters }\end{array}$ & 4.80 & 17.10 & 4.90 & 14.90 & 6.25 & 9.70 \\
\hline Kills "evil" characters & 93.70 & 82.90 & 90.20 & 87.20 & 93.75 & 89.40 \\
\hline Kills "good" characters & 6.30 & 17.10 & 9.80 & 12.80 & 6.25 & 10.60 \\
\hline
\end{tabular}

According to $74 \%$ of surveyed children a character should be rewarded for his or her actions (Table 3$)$. This opinion is shared by far more girls $(79.3 \%)$ than boys $(65.8 \%)$. In preferred films comes up a model of character that is not always lucky and successful, which was chosen 
by $37.5 \%$ of surveyed children as preferable. To respondents it is equally important, whether a character is in favour of fortune or a butterfinger. In this research category the answers of 10 -year-olds considerably differ from other age groups $-95.2 \%$ of them prefers a comic character, the earlier mentioned butterfinger. Also, children movies often bring up a theme of love between the man and woman. Research has shown that $56.7 \%$ of respondents like it when such a theme appears. However, it is worthwhile noticing that the responds of boys and girls are contrary. While $74.6 \%$ of girls like when romantic theme is introduced, $75.6 \%$ of boys do not prefer watching this type of situations. Surely, those preferences are connected with girl's greater sensibility.

Table 3. Behaviour of the movie character preferred by children aged 10-12.

\begin{tabular}{lllllll}
\hline & Girls & Boys & 10-year-olds & 11-year-olds & 12-year-olds & Overall \\
\cline { 2 - 7 } & $\%$ & $\%$ & $\%$ & $\%$ & $\%$ & $\%$ \\
\hline Is rewarded & 79.30 & 65.80 & 70.70 & 80.80 & 62.50 & 74.00 \\
\hline Is not rewarded & 20.70 & 34.20 & 29.30 & 19.20 & 37.50 & 26.00 \\
\hline Is not successful & 33.30 & 29.20 & 95.20 & 44.60 & 37.50 & 37.50 \\
\hline Is successful & 66.70 & 70.80 & 4.80 & 55.40 & 62.50 & 62.50 \\
\hline Falls in love & 74.60 & 24.40 & 56.10 & 55.30 & 62.50 & 56.70 \\
\hline Does not fall in love & 25.40 & 75.60 & 43.90 & 44.70 & 37.50 & 43.30 \\
\hline
\end{tabular}

The results obtained in the diagnostic survey underwent statistical analysis, which enabled determining the influence of the gender of surveyed children on the choice of preferred features and behaviours of movie characters (Table 4). An empirical value of test $\chi_{\text {emp }}^{2}$ for eleven, examined in survey, preferred features were indicated. In the range of the statistical significance from 0.001 to 0.05 five alternative hypotheses were assumed.

- Child's gender and movie character's gender. Since $\chi_{\text {emp }>}^{2} \chi_{\text {theo }}^{2}$ it is assumed that with probability 0.99 there are grounds to reject $\mathrm{H}_{0}$. The child's gender has an influence on the choice of the preferred movie character, which means that girls more often prefer female characters and boys the male ones. This relation is distinct but minor.

- Child's gender and movie character's age. Since $\chi_{\text {emp }}^{2} \chi_{\text {theo }}^{2}$ it is assumed that with probability 0.99 there are grounds to reject $\mathrm{H}_{0}$ The child's gender has an influence on the choice of the preferred age of movie character, which means that girls more often prefer teenage or child characters while boys prefer the adult ones. This relation is distinct but minor.

- Child's gender and movie character's possession of supernatural powers. Since $\chi_{\text {emp }}^{2} \chi_{\text {theo }}^{2}$ it is assumed that with probability 0.98 there are grounds to reject $H_{0}$. The child's gender has an influence on the choice of the preferred movie character on account of his or her possession of supernatural powers, which means that girls more often prefer characters with supernatural powers while boys prefer characters that are ordinary people. This relation is merely significant.

- Child's gender and movie character that inflicts pain. Since $\chi_{\text {emp }}^{2} \chi_{\text {theo }}^{2}$ it is assumed that with the probability 0.95 there are grounds to reject $\mathrm{H}_{0}$. The child's gender has an influence on the choice of the preferred movie character that inflicts pain on evil or good characters, which means that boys more often than girls choose characters that hurt evil characters. This relation is merely significant.

- Child's gender and movie character's love theme. Since $\chi_{\text {emp }}^{2} \chi_{\text {theo }}^{2}$ it is assumed that with probability 0.99 there are grounds to reject $\mathrm{H}_{0}$ The child's gender has an influence on the 
Tomasz HUK. Characteristic of the Most Popular Movie Characters among Children - Educational Contexts

PROBLEMS

OF EDUCATION

IN THE $21^{\text {st }}$ CENTURY Volume 56, 2013

choice of the preferred movie character that does or doesn't fall in love, which means that girls more often than boys choose characters that fall in love. This relation is distinct but minor.

Table 4. Statistical analysis.

\begin{tabular}{lllll}
\hline Established hypothesis & A & $\chi_{\text {emp }}^{2}$ & $\chi_{\text {theo }}^{2}$ & $\mathrm{r}_{\mathrm{c}}$ \\
\hline $\begin{array}{l}\text { Child's gender has an influence on the choice of preferred } \\
\text { movie character's gender }\end{array}$ & 0.001 & 30.345 & 10.83 & 0.29 \\
\hline $\begin{array}{l}\text { Child's gender has an influence on the choice of preferred } \\
\text { movie character's age }\end{array}$ & 0.001 & 22.648 & 10.83 & 0.21 \\
\hline $\begin{array}{l}\text { Child's gender has an influence on the choice of preferred } \\
\text { movie character on the account of his or her possession of } \\
\text { supernatural powers }\end{array}$ & 0.02 & 6.615 & 5.41 & 0.06 \\
$\begin{array}{l}\text { Child's gender has an influence on the choice of preferred } \\
\text { movie character that inflicts pain on good or evil characters }\end{array}$ & 0.05 & 4.330 & 3.84 & 0.04 \\
\hline $\begin{array}{l}\text { Child's gender has an influence on the choice of preferred } \\
\text { movie character that falls in love }\end{array}$ & 0.001 & 25.304 & 10.83 & 0.24 \\
\hline
\end{tabular}

\section{Discussion}

Presented research results are essential in designing and realization of the educational process at school. Each teacher should be acknowledged with his or her students' interests, as this knowledge creates new possibilities in the implementation of educational goals which in turn leads to the enhancement of the level of students' knowledge and skills. The presented research results correlate with other researches conducted in the field of media education. As a result, knowing about children's favourite movie characters might be significant for the teacher in the process of fulfilling children's expectations. Among a great set of expectations we can find those connected with a friendly attitude towards a student (Cohen et al., 1999). Meeting this expectation involves simple gestures on the teacher's part, such as starting a conversation between a student and the teacher about favourite movie characters. Knowledge about the canon of preferable features of movie characters makes the choice of appropriate movies for children easier. It is the first and most important step for a teacher which enables the effective integration of the art of film-making with curriculum (Cox, 1982).

The independent variable in the conducted research was the gender of respondents which was essential in various contexts connected with children's preferred movie characters. The popularity of female characters among girls and male among boys is relevant in the educational process at school. A female movie character is a role model for girls and a male is for boys. This rule has its reasons in research which indicates that boys achieve higher results in classes taught by a male teacher, rather than in classes taught by a female (Mussen et al., 1990). Therefore, gender is a significant factor in achieving high levels of education. In a natural way boys follow the example of male movie character as well as of a male teacher, while girls act similarly with female teachers. These discussions should be considered from a cultural perspective that appoints the function of woman and man in a particular community. Surveyed children are members of modern society that is based on principle of gender equality. Therefore the culture shall determine personality patterns emulated by children.

For the majority of surveyed children a movie character should be attractive which means fit, shapely, neat, well dressed, etc. The creation of such an image by media causes that children 
naturally try to emulate their idols. This phenomenon is causing much trouble among which we can distinguish the problem of excessive dieting of girls who are willing to be like their medial heroines. The combination of watching characters with an ideal appearance that are presented as strongly positive in movies, and simultaneously watching the obese ones that are punished e.g. by receiving negative remark, by young girls, creates a certain social-cultural model of behaviour. This model maintains that the development of body image and women's problems with eating partly arise from unrealistic standards of beauty and the media's role in broadcasting this message (Himes \& Thompson, 2007). Theses standards are constantly implemented into the culture of european and american societies, set trends and conditions which should be satisfied in order to achieve the success.

Determining the influence of mass media on individuals is very complicated and involves long-term observation (Juszczyk, 2004). However, child media research suggests strong connections between girls' psychophysical development and the body image presented in media. In spite of objective proof indicating that child media contains much information concerning external appearance that can have an effect on dissatisfaction with one's own body, very young girls seem not to be influenced by this news, contrary to their male colleagues. It may be caused by the fact that in their youth, children often play in imitating movie characters (therefore, they accept the role of character). However, the older and brighter children become, they stop playing in imitation and as a result they stop identifying themselves with characters. Data regarding such changes is necessary to determine the long-term consequences of early exposure to media, which illustrate beauty and ideals that are often the cause of dissatisfaction with their own body (Hayes \& Tantleff-Dunn, 2010).

Television has become almost omnipresent in the feature of a child's landscape culture of industrialised countries. Research considering children's education through films and TV programmes indicates with most probability that learning via media depends on children's developing social relations with on-screen characters. Therefore, it is important to formulate children's symbolical understanding of information presented in TV (Richert et al., 2011).

Media form a comfortable for them reality which does not always reflected in real life. Globalisation and general access to information. Globalization and general access to information causes that film producers, when making movies for children, locate heroes that are culturally universal in order to attract as many as possible spectators hat make profits.

Children are not always aware of mechanisms that run media whose goal is to attract as many audiences as possible. Research conducted in this field, mainly focuses on problems connected with discrepancy between what a child looks like and what he or she would like to look. It is worthwhile noting that media research rarely focuses on the positive use of information connected with movie characters, preferred by children. This occurs because contemporary media are the source of many dangers (Musioł, 2007).

\section{Conclusions}

Movie characters are characterized by specific features, which make them exceptional and unique to children watching them. Conducted research enabled to define a movie character that is a role model for children between the ages of 10-12 and to formulate answers to research problems.

Presented and analysed statements of children should be considered in relation to the social and cultural reality. In this aspect, the researches seam to be recognized ad the case study, because responders originate from the same social surroundings. It is necessary to add that proceeding process of globalization because of new media causes that the similar social surroundings are found in many countries. 
Tomasz HUK. Characteristic of the Most Popular Movie Characters among Children - Educational Contexts

PROBLEMS

OF EDUCATION

IN THE $21^{\text {st }}$ CENTURY Volume 56, 2013

The answer to the first problem indicates that the example of a movie character, preferred by children is different for girls and boys.

Five differences were determined, considering the character's features and his or her way of behaviour, which defines preferred by boys and girls movie characters. Therefore, girls prefer a character that is: a pretty girl or teenage girl, possessing supernatural powers, which she uses to fight with evil, hurting them. She never loses and always manages to accomplish missions, for which she should be rewarded. The plot of such a film should involve a love theme between the heroine and another character. Boys, however, prefer a movie character that is a handsome, adult man. He does not need to necessarily have any powers, yet he should be, though, fight with negative characters and inflict pain on them. He is able to successfully bring a mission to an end. Preferably, he should not be interested in women, much less fall in love with any of them. The differences between preferred examples of movie characters are statistically significant. It means that the defined movie character model for girls and boys might be used as a set of tips in the education of children between the age of 10-12. We should not be focusing only on characters known to children, which are an element of their entertainment. Valdemar W. Setzer and Lowell Monke (2001) caution us about such extremities. According to them, technology diverts attention from the things most needed in education. Therefore, a critical attitude is essential towards the choice of the favourite movie character, which is meant to be a benchmark in achieving the goals of teaching and devaluating the created world of values.

\section{References}

Bandura, A., Ross, D., Ross, S. A. (1963). Imitation of film-mediated aggressive models. The Journal of Abnormal and Social Psychology, 66, 3-11.

Bandura, A. (1986). Social Foundations of Thought and Action: A Social Cognitive Theory. Englewood Cliffs, NJ: Prentice-Hall.

Biskup, C., Pfister, G. (1999). I would like to be like her/him: are athletes role-models for boys and girls? European Physical Education Review, 5, 199-218.

Cohen, L., Manion, L., Marrison, K., (1999). A Guide To Teaching Practice. London: Routledge.

Cox, C. (1982). Children's Preferences for Film From and Technique. Language Arts, 59, 3.

Dorr, A., Kovaric, P., Doubleday, C. (1990). Age and content influences on children's perceptions of the realism of television families. Journal of Broadcasting and Electronic Media, 34, 377-397.

Frania, M. (2012). The importance of media education in schools in the process of building a knowledgebased society. Chowanna, 39, 303.

Guilford, J. P. (1964). Fundamental statistics in psychology and education. Warszawa: PWN, 157.

Hayes, S., Tantleff-Dunn, S. (2010). Am I too fat to be a princess? Examining the effects of popular children's media on young girls' body image. British Journal of Developmental Psychology, 28, 413-426.

Himes, S. M, Thompson, J. K. (2007). Fat Stigmatization in Television Shows and Movies: A Content Analysis. Obesity, 15, 712-718.

Juszczyk, S. (2004). Media influence on children and adolescents, The New Educational Review, $2,98$. Musioł, M. (2007). Pedagogization - family mediating. Chowanna, 29, 115.

Mussen, P. H., Conger, J. J, Kagan, J. (1990). Child Development and Personality. New York: Harper \& Row.

Richert, R. A., Robb, M. B., Smith, E. I. (2011). Media as Social Partners: The Social Nature of Young Children's Learning From Screen Media. Child Development, 82, 82-95. Roberts, D. F., Foehr, U. G. (2008). Trends in Media Use. Children and Electronic Media, 18.

Roberts, D. F., Foehr, U., Rideout, V. J. (2005). Generation M2: Media in the lives of 8 - to 18 -yearsolds. Menlo Park, CA: Kaiser Family Foundation.

Setzer, V. W., Monke, L. (2001). Challenging the applications: An alternative view on why, when and how computers should be used in education. In: R. Muffoletto (ed.), Education and technology: Critical and reflective practices, New Jersey: Hampton Press, Cresskill, 141-172. 
Tomasz HUK. Characteristic of the Most Popular Movie Characters among Children - Educational Contexts

$\mid$\begin{tabular}{l} 
PROBLEMS \\
OF EDUCATION \\
IN THE 21 $1^{\text {st }}$ CENTURY \\
Volume 56, 2013 \\
\hline 73
\end{tabular}

Advised by Agnaldo Arroio, University of Sao Paulo, Brazil

Received: October 12, 2013

Accepted: November 02, 2013

Tomasz Huk

Ph.D., Researcher, University of Silesia, Faculty of Pedagogy and Psychology, UI. Grażyńskiego 53, 40-126 Katowice, Poland.

E-mail: tomasz.huk@us.edu.pl

Website: http://www.pedagogika.us.edu.pl 